\title{
Experimental forward and reverse in situ combustion gasification of lignite with production of hydrogen-rich syngas
}

\author{
Yong Cui $\cdot$ Jie Liang $\cdot$ Zhangqing Wang $\cdot$ Xiaochun Zhang $\cdot$ Chenzi Fan $\cdot$ Xuan Wang
}

Received: 4 December 2013/Revised: 13 April 2014/ Accepted: 14 April 2014/Published online: 12 September 2014

(C) The Author(s) 2014. This article is published with open access at Springerlink.com

\begin{abstract}
This research focused on the feasibility of applying the forward and reverse combustion approach to the in situ gasification of lignite with the production of hydrogen-rich syngas $\left(\mathrm{H}_{2}\right.$ and $\left.\mathrm{CO}\right)$. The so-called forward combustion gasification (FCG) and reverse combustion gasification (RCG) approach in which oxygen and steam are simultaneously fed to the simulated system of underground coal gasification (UCG) was studied. A simulated system of UCG was designed and established. The underground conditions of the coal seam and strata were simulated in the system. The combustion gasification of lignite has been carried out experimentally for almost 6.5 days. The average effective content $\left(\mathrm{H}_{2}+\mathrm{CO}\right)$ of syngas during the FCG phase was $62.31 \%$ and the maximum content was $70.92 \%$. For the RCG phase the corresponding figures are $61.33 \%$ and $67.91 \%$. Thus, the feasibility of using RCG way for UCG has been demonstrated. The temperature profiles have been provided by using of 85 thermocouples during the model experiment, which portrayed the several nephograms of thermal data in the gasifier were of significance for the prospective gasification processes.
\end{abstract}

Keywords Underground coal gasification - Reverse combustion gasification · Forward combustion gasification · Hydrogen-rich · Syngas

\section{Introduction}

In essence the underground coal gasification (UCG) process is the in situ conversion of coal into syngas using two boreholes drilled from the surface, one for the injection of gasification agents and the other for the egress of the syngas. Accompanied by coal combustion to provide heat, the gasification agents react with the coal in a series of combustion and gasification reactions to form $\mathrm{H}_{2}, \mathrm{CO}, \mathrm{CH}_{4}, \mathrm{CO}_{2}$ and other minor constituents (Friedmann et al. 2009; Evgeny and Arvind 2009). UCG technology differs from conventional coal gasification in surface reactors, in that it is an invisible process, so it is difficult to control the reaction process and consistently produce hydrogen-rich syngas in the

Y. Cui · J. Liang $(\bowtie) \cdot$ Z. Wang $\cdot$ X. Zhang $\cdot$ C. Fan $\cdot$ X. Wang School of Chemical and Environmental Engineering, China University of Mining \& Technology (Beijing), Beijing 100083, China

e-mail: ucgrc@sohu.com underground situation (Friedmann et al. 2009). While they were engaged in field trials in the 1980s, several researchers began to establish simulation systems of UCG processes so as to study the actual phenomena and reactions in the UCG cavity (Skafa 1960; Singh et al. 1980; Hurloff 1983; Park and Edgar 1987; Prabu and Jayanti 2011).

At present, there are three configurations of experimental UCG units (Liu et al. 2011; Stanczyk et al. 2011; Krzysztof et al. 2012). The UCG model reactor was established in the shape of a cylinder with the external contour size $7.4 \mathrm{~m}$ (length) and $3.5 \mathrm{~m}$ (diameter) by researchers in the State Key Laboratory of Coal-Based Low Carbon Energy ENN Group Co., Ltd. Specifically, there were four windows to enable observations of coal combustion to be available, using closed circuit industrial television. A total of 96 thermocouples were located in the coal seam and strata to measure temperature gradients during the trial (Stanczyk et al. 2011). The ex situ reactor (Liu et al. 2011) was simulated in the gasification of lignite and hard coal with oxygen and enriched air (air + oxygen) 

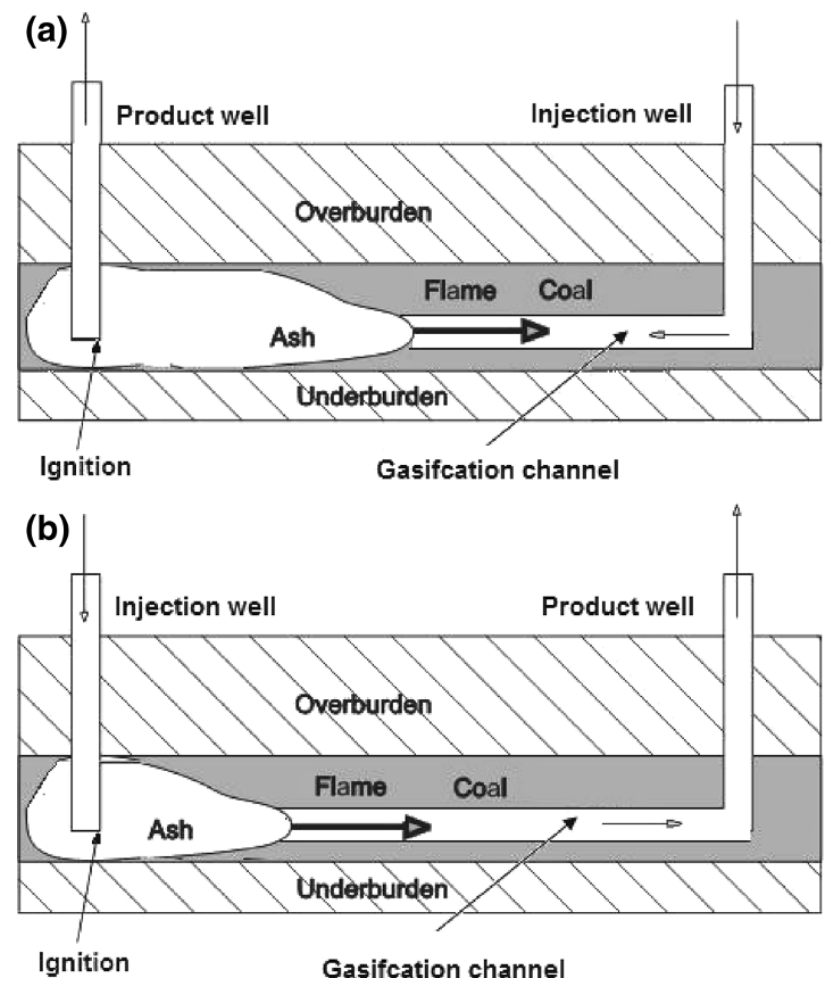

Fig. 1 Diagrammatic sketches of reverse combustion gasification (a) and forward combustion gasification (b)

in the 50 and $30 \mathrm{~h}$ experiments, respectively. Only the oxygen gasification experiment was relatively successful regarding product gas quality. Although the two-stage gasification approach in which oxygen and steam were separately fed to the reactor was studied in both of these experimental UCG units, hydrogen-rich syngas should be obtained (Liu et al. 2011; Krzysztof et al. 2012), but the practical operation of the UCG process is difficult as regards the measurement of the temperature in the reaction zone and the control of the switching between oxygen and steam stages according to the change in temperature. It is concluded that the two-stage gasification approach is not suitable for application to UCG. The UCG system in the China University of Mining and Technology was investigated in a model experiment of underground coal gasification and is the subject of this paper.

Several different approaches have been applied to UCG technology (Yang and Liu 2003; Yang et al. 2003; Yang 2004; Khadse et al. 2007; Yang et al. 2008; Shugin et al. 2009), including reverse combustion gasification (RCG) and forward combustion gasification (FCG). In RCG, the gasification agents are injected into one borehole and coal is ignited in the other borehole so that the flame propagates towards the opposite direction of gas flow in the channel as shown in Fig. 1a. In the FCG process coal is ignited in the injection borehole, and the flame propagates along the direction of gas flow in the channel as depicted in Fig. $1 \mathrm{~b}$.
Generally forward and reverse combustion approaches are used in shaftless type UCG process. In the practical operations, reverse combustion was widely applied to link the injection and production wells in UCG (Blinderman et al. 2007), but was seldom used to gasify coal. Forward combustion has been usually applied to gasify the coal seam with appropriate gasification agents (Skafa 1960; Blinderman et al. 2007). When the flame gradually moved to the product borehole in the late stage of FCG, the huge cavity should be formed in the coal seam due to coal combustion gasification and overburden roof spalling. It made coal gasification efficiency reduce and the quality of production gas decrease. The high intensity forward gasification process would be difficult to be continued. The reasons are as follows (Yang et al. 2008): (1) The dry distillation zone becomes shorter and shorter in the later forward gasification. (2) The reaction activity of coal significantly decays after coal seams underwent dry distillation during forward gasification. (3) The reaction rates of coal combustion and gasification fell for descending concentration of gasification agents absorbed on coal surfaces of the cavity wall. To make coal seams further gasify and enhance syngas quality, the injection borehole and product borehole should be exchanged in practical operation. Then coal seams will be continued to gasify by shifting the direction of injection gas. New gasification conditions formed again. If the gasification flame moved to the direction of injection gas flow, therefore the residual coal seams around former product borehole would not be gasified. It is the waste for coal resource. In order to keep on gasifying residual dried and distilled zone, and solve the problem of the late stage of FCG, the reverse combustion gasification could be applied in UCG process. To research the feasibility and characteristics of the RCG approach, gasification experiments were performed in a system of UCG to simulate the FCG and RCG processes.

\section{Materials and methods}

Large-scale lignite and rock blocks were sampled at the same mine from the region and placed in the simulated UCG gasifier. The oxygen, enriched oxygen and steam as gasification agents were continuously fed into the gasifier in the model experiments. Detailed conditions used for the simulated underground gasification are described below.

2.1 Simulation of the inclined lignite seams and strata in simulated UCG units

The diagram of the simulated system for UCG for lignite is shown in Fig. 2. It consisted of gas flow inlets with valves, flow meters and regulators, gas flow temperature and 


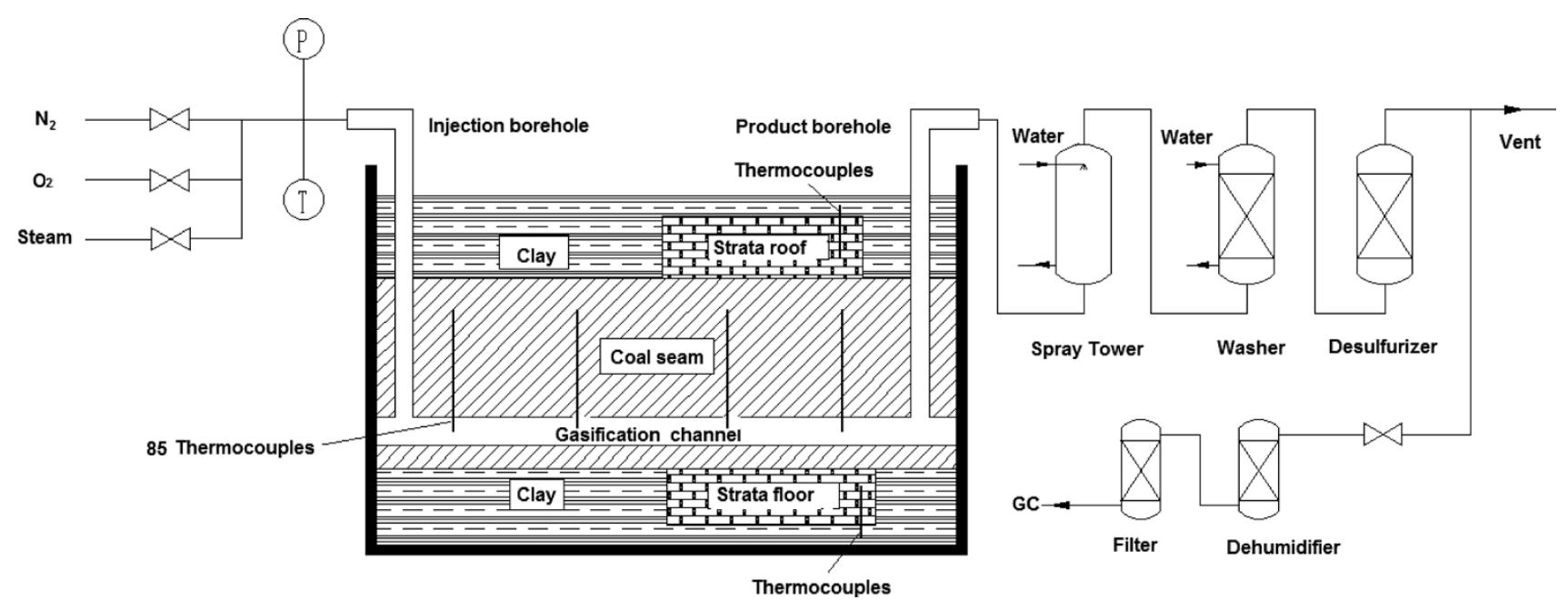

Fig. 2 Diagram of the units used for experimental lignite gasification in the UCG simulation

pressure instrumentation, the simulated UCG gasifier, spray tower, gas washer, desulfurizer, dehumidifier, gas filter system, and a gas chromatograph.

A pilot-scale simulated underground gasifier was constructed in the rectangular shape with the internal dimensions of $4.45 \mathrm{~m}$ (length) $\times 1.17 \mathrm{~m}$ (width) $\times 1.57 \mathrm{~m}$ (height). External walls of the gasifier were composed of fire retardant layers, thermal insulation layers, stainless steel sealed layers and reinforced concrete anti-pressure layers in order from inside to outside. There were some holes for measurement and observation structured on the gasifier body, hereinto, 19 holes were used to measure experimental temperatures, six holes were used to monitor the gasifiers pressures, and four boreholes used to observe the internal conditions of gasifier by cameras installed in them. Otherwise, four holes were utilized as injection gas inlets or production gas outlets.

Gasification agents like oxygen or oxygen-steam mixture gas were fed into the pilot system by supplying gas equipment. Oxygen agent was supplied from ten steel cylinders of parallel connection under $0.2 \mathrm{MPa}$ pressure. Water was changed into saturated aqueous vapor under pressure of $0.7 \mathrm{MPa}$ in the electric steam generator with its rated evaporation capacity of $80 \mathrm{~kg} / \mathrm{h}$. In view of the pilot system safety, valve and steel cylinder of nitrogen were installed in the supplying system to extinguish a fire in the gasifier in case of emergency.

The product gas was transported into a suit of pilot-scale purification system by a $0.10 \mathrm{~m}$ diameter pipe. The purification system was mainly composed of spray tower, gas washer and desulfurizer. The product gas suffered from purification process and was combusted at flare stack. Partial the syngas flow was led to the online gas chromatograph for component analysis. Before the sample gas entered into chromatographic columns it need be further purified by the dehumidifier and gas filter made of quartz.

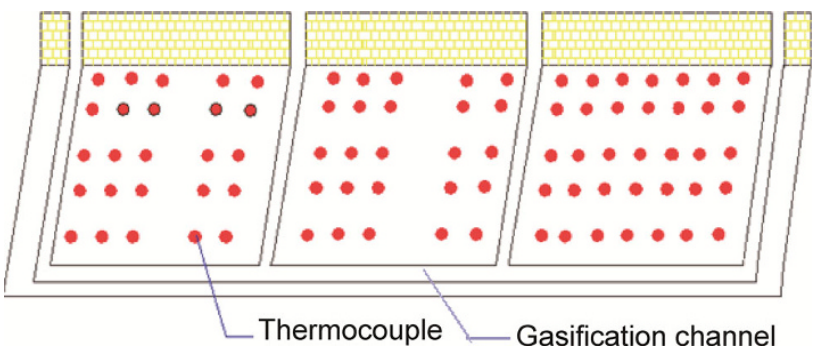

Fig. 3 Diagram of the 85 thermocouple horizontally located in coal seam

The schematic view of the simulated lignite seam and strata is shown in Fig. 2. The gasification channel was excavated in the bottom of the coal seam with a length of $4 \mathrm{~m}$ and a diameter of $0.08 \mathrm{~m}$. The strata including roof and floor were established in the construction of the gasifier whose design is as follows: Grit stone and shale were laid in the strata floor, and two grit stones and shales were laid in the strata roof one by one. Before the lignite seams were constituted, the floor comprised rock and clay with a $17^{\circ}$ inclination. The dimensions of the lignite block were $0.4 \mathrm{~m} \times 0.5 \mathrm{~m} \times 0.5 \mathrm{~m}$. The roof comprised a layer with a thickness $0.5 \mathrm{~m}$ that was filled with rock blocks and clay above the coal seams. The expanded perlites with $0.1 \mathrm{~m}$ thickness were used as an insulating layer above the roof.

During the experiments, several parameters need to be monitored. The temperature data were collected by means of $\mathrm{Ni}-\mathrm{Cr} / \mathrm{Ni}-\mathrm{Si}$ (K type) armored thermocouples uniformly placed in the seam seen in Fig. 3. This provides crucial information about coal combustion/gasification and explains the experimental results. The mass flow of the product syngas was measured at the outlet with a flow meter and its composition was continuously monitored by 
Table 1 Proximate and ultimate analysis of lignite

\begin{tabular}{|c|c|c|c|c|c|c|c|}
\hline \multicolumn{3}{|c|}{ Proximate analysis $w_{\text {ad }}(\%)$} & \multicolumn{5}{|c|}{ Ultimate analysis $w_{\text {daf }}(\%)$} \\
\hline$M$ & $A$ & $V$ & $\mathrm{C}$ & $\mathrm{H}$ & $\mathrm{O}$ & $\mathrm{N}$ & $S$ \\
\hline 32.5 & 16.32 & 46.24 & 74.46 & 4.80 & 18.34 & 1.41 & 0.98 \\
\hline
\end{tabular}

the two-TCD online gas chromatograph (Shimadzu GC2014) every $12 \mathrm{~min}$, and the sampling interval was $3 \mathrm{~min}$.

\subsection{Materials}

The coal seam comprised of blocks of lignite and strata and was simulated by blocks of rocks supplied from the coal mine. The proximate and ultimate analysis of the lignite samples acquired according to appropriate standards are presented in Table 1.

\section{Experimental procedure}

\subsection{Cold-state test}

Cold tests should be performed to check that all systems are leak-free. All valves (both inlet and outlet) were open. The air was blasted in from the injection inlet by means of a blower, and the product gas was released from the outlet. The air flow at both inlet and outlet was recorded to calculate gasifier leakage. Additionally, the pressure at the inlet and outlet and in the gasifier was monitored. Gasifier leaks could be detected using soap-water. When the blast volume was in the range of $2.5-10 \mathrm{~m}^{3} / \mathrm{h}$, and the gasifier leakage was $<3 \%$, the test data can be recorded. In the cold-test the leak rate was $2.8 \%$. When the static pressure of the gasifier reached $25 \mathrm{kPa}$, pressure release took $35 \mathrm{~min}$. This means that the velocity of pressure release was $0.714 \mathrm{kPa} / \mathrm{min}$ which satisfied ignition requirements.

\subsection{Ignition}

At first, an electric igniter was placed inside the gasification channel from the injection borehole. Pure oxygen was blown into the coal seam, and the electricity turned on. It could be seen that the coal seam was ignited because the temperature in the gasification channel exceeded $600{ }^{\circ} \mathrm{C}$ (Stanczyk et al. 2011). Subsequently, the ignition process was terminated. Next, the electric igniter was removed and pure oxygen was passed to the gasifier. The gasification process began after a $2 \mathrm{~h}$ ignition period.

The experiments were divided into three phases. In phase I, $98 \%$ oxygen was fed to the reactor to heat up the coal seam and to provide sufficient heat energy before feeding oxygen and steam. In phase II, oxygen and steam were continuously supplied to the reaction zone, and the FCG experiment was performed. The primary purpose of phase II was to explore the optimal ratio of steam to oxygen and the flow rate required to obtain high-quality syngas in the FCG process. This was achieved by directly analyzing the product gas composition under different operational conditions and various temperature profiles in the coal seam and strata. In phase III, $93 \%$ oxygen and steam were reversely supplied to the gasifier for improved syngas quality in the last stage of the UCG process. The characteristics and feasibility of RCG were largely investigated based on the RCG technique in phase III.

\section{Results and discussion}

Model experiments in the UCG gasifier were performed to investigate lignite gasification with oxygen or oxygensteam in the forward and reverse combustion processes.

\subsection{Oxygen gasification (phase I)}

Pure oxygen was supplied to the gasifier and phase I was initiated after ignition. In the next $26 \mathrm{~h}$ only pure oxygen was fed to the gasifier with a flow rate of $3.6-5 \mathrm{~m}^{3} / \mathrm{h}$ to heat the coal seam and to accumulate adequate heat energy for subsequent lignite gasification.

The composition of the product gas, the average gas composition as well as the heating value of the product gas in phase I of lignite seam gasification are presented in Fig. 4; Table 2.

The quality of the product syngas was relatively high although steam was not fed in this phase $(2-28.5 \mathrm{~h})$. The average heating value of the syngas was $9.13 \mathrm{MJ} / \mathrm{m}^{3}$. The average value of effective syngas composition $\left(\mathrm{CO}\right.$ and $\left.\mathrm{H}_{2}\right)$ reached about $58 \%$, and $\mathrm{H}_{2} / \mathrm{CO}$ was equal to 1.58 since lignite contained a relatively high moisture content of $>30 \%$. At high temperatures, the moisture changed into steam and reacted with the coal to generate hydrogen and

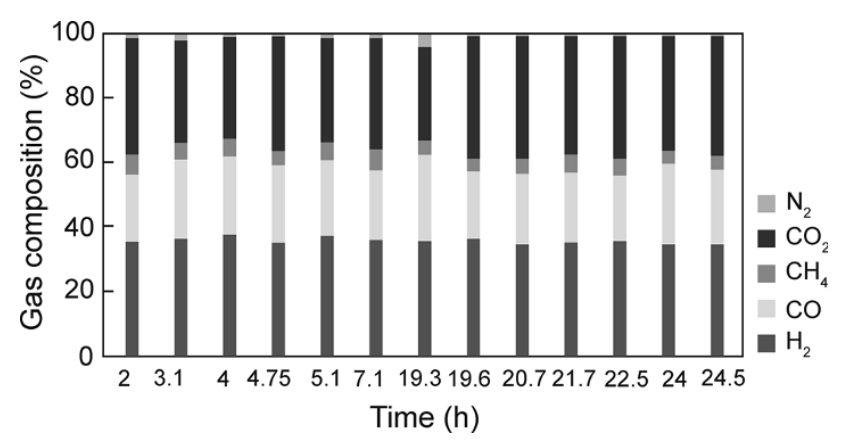

Fig. 4 The change of product syngas composition in phase I 
Table 2 Average syngas composition and heating values of product syngas in phase I, II (FCG) and III (RCG)

\begin{tabular}{lcccccc}
\hline $\begin{array}{l}\text { Gasification } \\
\text { phase }\end{array}$ & Time (h) & $\begin{array}{l}\mathrm{H}_{2} \\
(\%)\end{array}$ & $\begin{array}{l}\mathrm{CO} \\
(\%)\end{array}$ & $\begin{array}{l}\mathrm{CH}_{4} \\
(\%)\end{array}$ & $\begin{array}{l}\mathrm{CO}_{2} \\
(\%)\end{array}$ & $\begin{array}{l}\text { Heating } \\
\text { value } \\
\left(\mathrm{MJ} / \mathrm{m}^{3}\right)\end{array}$ \\
\hline $\begin{array}{c}\text { Pure oxygen } \\
(98 \%)\end{array}$ & $2-28$ & 35.5 & 22.5 & 4.91 & 35.3 & 9.13 \\
FCG Phase & $28.5-117$ & 39.9 & 22.9 & 3.49 & 32.7 & 9.20 \\
RCG phase & $121-152$ & 39.7 & 21.7 & 1.71 & 36.2 & 8.30 \\
\hline
\end{tabular}

CO. Though the major purpose of this step was to preheat the coal seam, gasifying high moisture lignite could produce hydrogen-rich syngas in phase I. The coal seam temperature and composition of syngas were crucial factors to decide the time when the switch to pure oxygen should take place. The temperature profiles are presented in Fig. 12. The temperature of the coal seam changed from 300 to $1,000{ }^{\circ} \mathrm{C}$ after $15 \mathrm{~h}$ (Fig. 13a, b). The temperature in the combustion zone was relatively high, attributable to the release of a great deal of heat and volatiles by reaction of lignite with pure oxygen. The combustion of volatiles significantly heated the coal. The process is referred to as the main overall reaction (Yang 2004; Perkins and Sahajwalla 2005; Yang et al. 2007).

$$
\begin{aligned}
& \text { Pyrolysis for coal: } \rightarrow \mathrm{C}+\mathrm{CO}+\mathrm{CO}_{2}+\mathrm{H}_{2}+\mathrm{CH}_{4} \\
& \quad+44.7 \mathrm{MJ} / \mathrm{k} \text { mol } \\
& \text { Carbon oxidation: } \mathrm{C}+\mathrm{O}_{2} \rightarrow \mathrm{CO}_{2}-394 \mathrm{MJ} / \mathrm{k} \text { mol } \\
& \text { Volatiles combustion: } 2 \mathrm{CO}+\mathrm{O}_{2} \rightarrow 2 \mathrm{CO}_{2} \\
& \quad-571 \mathrm{MJ} / \mathrm{k} \text { mol } \\
& \quad \mathrm{H}_{2}+1 / 2 \mathrm{O}_{2} \rightarrow \mathrm{H}_{2} \mathrm{O}-242 \mathrm{MJ} / \mathrm{k} \mathrm{mol} \\
& \mathrm{CH}_{4}+2 \mathrm{O}_{2} \rightarrow \mathrm{CO}_{2}+2 \mathrm{H}_{2} \mathrm{O}-890 \mathrm{MJ} / \mathrm{k} \mathrm{mol}
\end{aligned}
$$

There was sufficient thermal energy for moisture in the lignite $(30 \%)$ to evaporate at high temperature. The steam decomposition reaction with char took place in the gasification channel. The higher content of hydrogen is attributable to the steam gasification reaction, favored at temperatures above $800{ }^{\circ} \mathrm{C}$ (Yang and Liu 2003). Moreover, the composition of the syngas from 5 to $28 \mathrm{~h}$ of the phase I state remained constant and the temperature profiles in the combustion zone were stable.

The temperatures of the outlet syngas, the strata floor and the roof reflect the status of the UCG gasifier as depicted in Fig. 5. In this phase, the temperature of outlet syngas rose from 20 to $94{ }^{\circ} \mathrm{C}$, with a rate of $2{ }^{\circ} \mathrm{C} / \mathrm{h}$. The temperature of roof rose from 20 to $76{ }^{\circ} \mathrm{C}$, with a rate of $2.15{ }^{\circ} \mathrm{C} / \mathrm{h}$. The temperature of floor rose from 20 to $40{ }^{\circ} \mathrm{C}$, with a rate of $0.76{ }^{\circ} \mathrm{C} / \mathrm{h}$. The heating rate of outlet syngas, strata floor and roof was relatively slow as the main purpose of this phase was to preheat the coal seam and

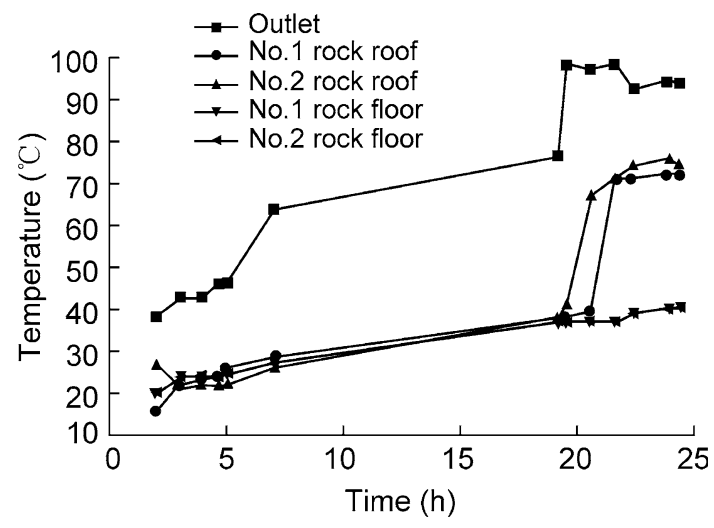

Fig. 5 Change in temperature of outlet syngas and of strata floor and roof in phase I

accumulated thermal energy, in preparation for latter phase (Stanczyk et al. 2011; Krzysztof et al. 2012).

The oxygen gasification process lasted for $26 \mathrm{~h}$ in which $387 \mathrm{~m}^{3}$ syngas were produced. An average carbon consumption rate was $0.336 \mathrm{~kg} / \mathrm{m}^{3}$ carbon and $299 \mathrm{~kg}$ coal was gasified. The average gas production rate in the phase I was $14.9 \mathrm{~m}^{3} / \mathrm{h}$.

\subsection{Oxygen and steam FCG (phase II)}

Following phase I, steam and pure oxygen were injected into the gasifier to increase $\left(\mathrm{H}_{2}+\mathrm{CO}\right)$ content in syngas to about $60 \%$. Experiments during phase II were carried out between about 28 and $117 \mathrm{~h}$ of the test. This phase was divided into two stages. One involved pure oxygen and steam gasification for $52.5 \mathrm{~h}$, and the other was oxygenenriched air and steam gasification for $36.5 \mathrm{~h}$. The pure oxygen supply rate was in the range $4-9 \mathrm{~m}^{3} / \mathrm{h}$. The rate of steam supplied should be adjusted according to the oxygen supply rate for keeping the $\left(\mathrm{H}_{2}+\mathrm{CO}\right)$ content in the syngas of about $60 \%$, in which $\mathrm{H}_{2}$ accounted for $35 \%$ $45 \%$ and $\mathrm{CO}$ for $20 \%-30 \%$. The supply rate of the stream was increased as the hydrogen content decreased, whereas the supply rate of the stream was reduced as $\mathrm{CO}$ content decreased to $<20 \%$. The main aim of the experiment in phase II was to establish the optimal volume ratio of steam to oxygen. The optimal range was found to be in the range 1.5:1-2:1 (Yang et al. 2008).

In the gasification process, temperature was usually a decisive factor, because this not only affected the composition of the product gas but was also helpful in determining the progress of the gasification reaction. It is important that a high temperature in the combustion zone be maintained in the actual UCG process by adjusting the flow rate of gasification agents and the $\mathrm{H}_{2} \mathrm{O} / \mathrm{O}_{2}$ ratio (Perkins and Sahajwalla 2005; Prabu and Jayanti 2011). Gasification theory indicates that steam should be 


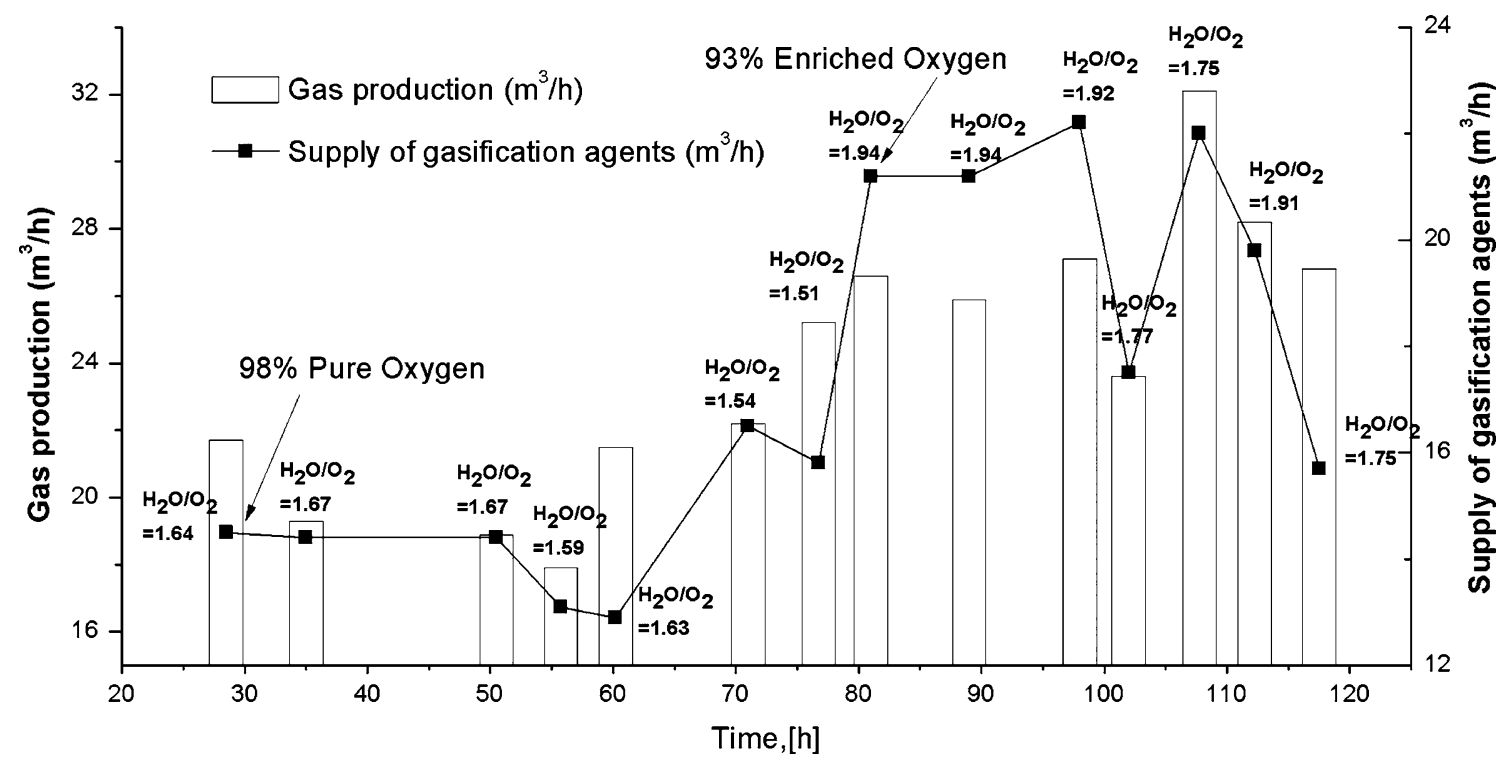

Fig. 6 Rates of gas production as a function of gasification agents supply rates and total supply of gas during phase II

decomposed with a high reaction rate to ensure a hydrogenrich product gas while the gasification temperature exceeds $1,000{ }^{\circ} \mathrm{C}$ (Yang et al. 2007; Hossein et al. 2010). The production rates of $\mathrm{CO}$ and $\mathrm{H}_{2}$ content were determined by two main reactions (Alejandro and Fanor 1998):

Steam gasification reaction: $\mathrm{C}+\mathrm{H}_{2} \mathrm{O}(\mathrm{g})$

$$
\rightarrow \mathrm{CO}+\mathrm{H}_{2}+131.1 \mathrm{MJ} / \mathrm{kmol}
$$

Water - gas - shift reaction: $\mathrm{CO}+\mathrm{H}_{2} \mathrm{O}(\mathrm{g})$

$$
\rightarrow \mathrm{CO}_{2}+\mathrm{H}_{2}-41 \mathrm{MJ} / \mathrm{kmol}
$$

The key factor in producing hydrogen-rich product gas is the steam gasification reactions, but steam decomposition is a highly endothermic reaction. This led to a significant decrease in the rate of water decomposition and chars gasification when the temperature dropped below $700{ }^{\circ} \mathrm{C}$ Yang et al. 2007; Hossein et al. 2010). The watergas-shift reaction made a significant impact on the composition of the syngas. The $\left(\mathrm{CO}+\mathrm{H}_{2}\right)$ content of the syngas obviously increased at higher temperatures. The melting point of lignite ash was about 1,300 and, for this reason, the supply ratio of oxygen to steam was adjusted to maintain a gasifier temperature between 1,000 and $1,300{ }^{\circ} \mathrm{C}$ in the gasifier. The rates of gas production as a function of gasification agents supply rates and composition are presented in Fig. 6.

The average ratio of steam and oxygen in the first stage was about 1.60, but it was about 1.85 in the second stage to keep temperatures in the range between 1,100 and $1,200{ }^{\circ} \mathrm{C}$. During phase II, the temperature in the gasifier was often observed to ensure suitable conditions for water decomposition. The most favorable gasification conditions to produce syngas in the gasifier were reached between 50

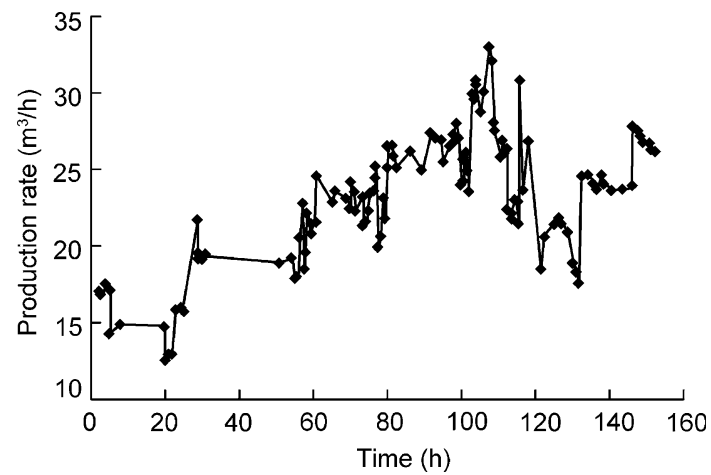

Fig. 7 Changes in gas production rate during the gasification experiment

and $120 \mathrm{~h}$ from the beginning of the test, as shown in Fig. 7 , since relatively high levels of thermal energy had been accumulated and the gasification zone was well developed (Krzysztof et al. 2012).

When the rate of product gas reached $25.1 \mathrm{~m}^{3} / \mathrm{h}$ and this status had been maintained for $2 \mathrm{~h}$, the pure oxygen agent was changed into $93 \%$ enriched oxygen, of interest for economic reasons. In the later stage of phase II, the rate of supply of oxygen and steam steadily increased. The supply rate of oxygen increased to maintain high temperature of about $1,000{ }^{\circ} \mathrm{C}$ in the UCG gasifier. The supply rate of steam was increased to promote water decomposition into hydrogen-rich combustible gas under high temperature conditions. The average product gas rate steadily increased to $26.9 \mathrm{~m}^{3} / \mathrm{h}$, and the effective content of the syngas is shown in Fig. 8. The results showed that the gasifier worked well, and hydrogen-rich syngas was produced in 


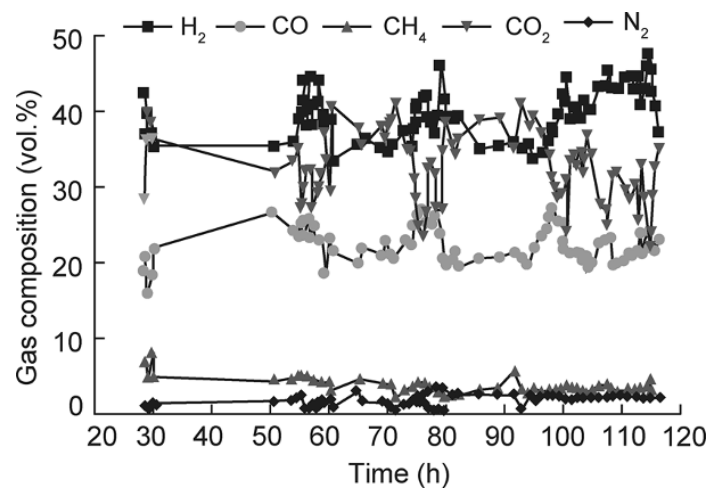

Fig. 8 The composition of product gas during phase II

the later stage of phase II. Changes in gas production rate during the complete gasification experiment are presented in Fig. 7. The temperature profiles in phase II were presented in Fig. 13c, d and e. The high temperature field gradually extended from the injection borehole to the middle of the gasifier. The maximum temperature reached $1,300{ }^{\circ} \mathrm{C}$ and the oxidation/gasification reaction zone moved to the center. These experimental results showed that the lignite was gasified to produce a hydrogen-rich syngas through the use of $93 \%$ enriched-oxygen gasification. Thus, the gasification experiment may be carried out in the future with a lower concentration of oxygen in the oxygen-enriched air.

At the beginning of phase II, the strata temperatures were low (Fig. 9) since vertical propagation of the reaction zone took place relatively slowly (Krzysztof et al. 2012). Conduction was a less significant contributor to heat transfer. This is attributed to the low thermal conductivity of the lignite seam and strata (Yang and Liu 2003). In the latter stage of phase II, strata temperatures rapidly increased because the flame front moved to the gasifier center. Nevertheless, the roof temperatures rose more slowly than the floor temperatures in the period 75-91 h since the distance of the roof from the flame front was longer than that of the floor. The heating rate for the roof was lower than that for the floor, brought about by conduction when the coal was combusted and gasified in the middle of the channel. The highest temperature of the roof was at $1,300{ }^{\circ} \mathrm{C}$ while that of the floor was $1,135{ }^{\circ} \mathrm{C}$. This phenomenon shows that it is important to maintain heat transport by means of radiation because the peak temperature is very high (Perkins and Sahajwalla 2007), when the top of the gasification cavity of coal seam reached the strata roof. Moreover, the strata roof is located at the top of the combustion flame. The result showed that the reaction zone of oxidation/gasification had gradually moved to the gasifier center.

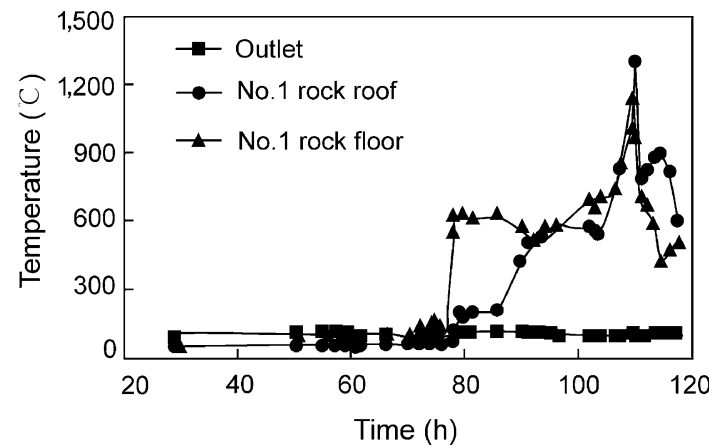

Fig. 9 Change in the temperature of the outlet syngas, strata floor and strata roof in phase II

The oxygen and steam FCG process lasted for $91 \mathrm{~h}$ in which $2,170 \mathrm{~m}^{3}$ syngas were produced, $0.316 \mathrm{~kg} / \mathrm{m}^{3}$ carbon was consumed and $1,580 \mathrm{~kg}$ coal was gasified. The average gas production rate in this gasification period was $23.7 \mathrm{~m}^{3} / \mathrm{h}$.

The average hydrogen content obtained in this period was less than $45 \%$, which demonstrated that appropriate thermal conditions for the steam decomposition as well as for the intensification of the pyrolysis phenomena were not achieved, because the UCG gasifier was limited in the accumulation of thermal energy and the gasified lignite exhibited a low effective carbon content.

\subsection{Oxygen and steam RCG (phase III)}

The quality of syngas declined in the later stages of phase II because a large cavity was formed along the gasification channel. The oxygen concentration in the surface of the incandescent coal was so low that the coal combustion reaction rate declined. In addition, the reactivity of the coal declined because the residual coal was partially pyrolyzed and was converted into char, which possessed a lower reactivity owing to the larger pore diameter (Alejandro and Fanor 1998; Yang et al. 2008). The high intensity forward gasification process would be difficult to be continued. Then, the RCG approach was proposed to solve the problem in the late stage of UCG process. And a new UCG technique of the reverse combustion gasification combined with forward combustion gasification creatively formed. The objective of reverse combustion gasification is optimized to the UCG process further. At the moment the injection and product boreholes were switched, oxidants were injected into the product borehole and product gas was removed from the injection borehole, but the flame then moved to the product borehole. At the beginning of phase III, the steam was blown into the two boreholes to remove the product gas. The $93 \%$ oxygen was injected from the product borehole to improve the gasifier 
temperature, and its initial supply rate was $5 \mathrm{~m}^{3} / \mathrm{h}$. After $0.5 \mathrm{~h}$, the temperature of the gasifier center returned to above $1,000{ }^{\circ} \mathrm{C}$, and the steam was fed continuously until the total process was terminated.

The flame front propagated faster with oxygen than with air (Skafa 1960). The global combustion process can be expressed as:

$\mathrm{C}+(1-a / 2) \mathrm{O}_{2} \rightarrow a \mathrm{CO}+(1-a) \mathrm{CO}_{2}$

The mass concentration of oxygen and the heat release were crucial factors to maintain RCG. The relationship between the initial mass concentration of oxygen $\left(\rho \mathrm{O}_{2}\right)_{0}$ and heat release $Q_{h}\left(\mathrm{~T}_{\mathrm{b}}, \ldots\right)$ can be expressed by (Blinderman et al. 2007; Blinderman and Klimenko 2007; Dmitry et al. 2010):

$Q_{h}\left(T_{b, \ldots}\right)=\bar{\lambda}\left(\frac{\partial T}{\partial x}\right)_{-r}=\sqrt{\left(\rho_{O_{2}}\right)_{0} \bar{A} \theta \overline{\lambda_{r}} \varphi\left(T_{b}\right)}$,

where subscript " $-r$ " denotes the value just upstream of the reaction zone, $\bar{\lambda}_{r}$ is the diffusion coefficient and $\varphi\left(T_{b}\right)$ is indicated by:

$$
\begin{aligned}
\varphi\left(T_{b}\right) & =\int_{-\infty}^{T_{b}} K(T) \mathrm{d} T=\frac{K_{d}}{Z} \ln \left(1+\frac{K_{r}\left(T_{b}\right)}{K_{d}}\right) \\
Z & \equiv \frac{E_{a} / R}{T_{b}^{2}} \\
\theta & =\frac{2 H\left(\mu_{s}^{-}\right)}{\alpha}
\end{aligned}
$$

$H\left(\mu_{s}^{-}\right)$is the enthalpy of combustion reaction. Since coal was incandescent in the later stages of gasification, the coal had been preheated prior to combustion. The flame can readily propagate upstream and a higher temperature in the combustion zone leads to more intense reactions and an increase in the burning rate. Then, a greater mass flow of oxygen is needed to sustain the higher temperature flame front. If the flame temperature is low, the flame cannot move at an appreciable speed upstream since this would induce additional heat losses. The flame at very low temperatures or low flow rates of oxidants would be practically non-existent. As the flow of oxidants increases, the flame temperature rises (Blinderman et al. 2007; Blinderman and Klimenko 2007; Dmitry et al. 2010). To ascertain the appropriate enriched oxygen flow, the oxygen supply rate can be calculated using the above-mentioned equations. Some parameters in the calculations were selected as follows; $A=1.06 \mathrm{e} 4 \mathrm{~min}^{-1}, \quad E a=12,331.5 \mathrm{~J} / \mathrm{mol}, \quad T_{b}=$ $1,000 \mathrm{~K}, a=0.4$; and other parameters were derived from the literature (Gort 1995; Hans et al. 2008; Blinderman et al. 2007; Blinderman and Klimenko 2007; Dmitry et al. 2010). According to our calculations, the initial supply rate of enriched oxygen was $5 \mathrm{~m}^{3} / \mathrm{h}$. When the temperature of the gasifier center exceeds $1,000{ }^{\circ} \mathrm{C}$, the oxygen mass flow

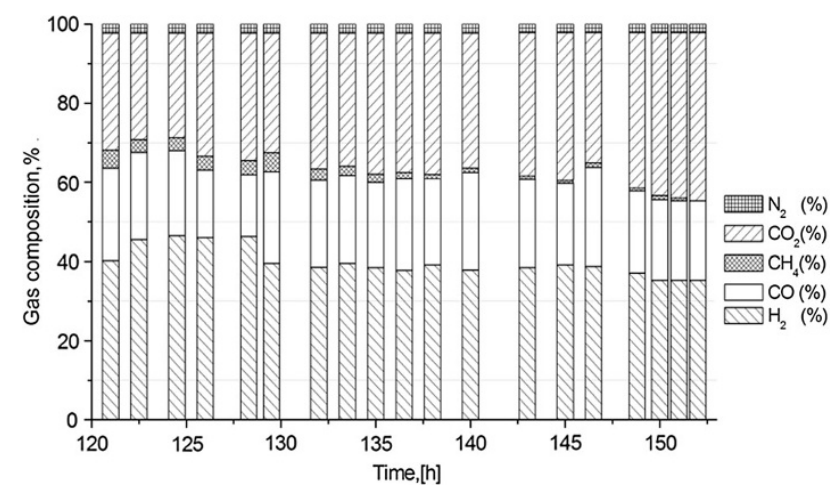

Fig. 10 The composition of product gas in the phase III

gradually increased to sustain coal/char combustion as shown in Fig. 10. The rate of production of syngas increased accordingly. The highest temperature in the UCG gasifier was $1,100{ }^{\circ} \mathrm{C}$ as seen in Fig. 13f. Simultaneously, the ratio of oxygen to steam in the supply gas was adjusted to maintain the appropriate temperature in the UCG gasifier for coal gasification. The experimental results showed that the RCG approach performed well and it was feasible as a UCG process.

The ratios of steam and oxygen in the supply gas should be adjusted to produce high-quality syngas. The composition of the syngas, the average gas composition and the heating value obtained in phase III are shown in Fig. 10; Table 2. The average gas production rates as a function of supply rates of the gasification agents and its composition are given in Fig. 11. The average ratio of steam to oxygen was 1.68 , which was lower than the value in the latter stages of phase II. These results agreed with those reported by Skafa (1960). In practical UCG operations, a pearshaped cavity should be formed in the gasification channel by forward combustion, while a predominantly tube-like cavity could be made by the reverse combustion approach (Skafa 1960; Sateesh et al. 2010). This resulted in a much lower consumption of coal for the reverse combustion process. The concentration of $\mathrm{CH}_{4}$ gradually decreased from about $3.9 \%$ at the beginning of the RCG to zero at the end of phase III, which demonstrates that the gasification process would finish and that $\mathrm{H}_{2}$ or $\mathrm{H}_{2} \mathrm{O}$ would not react with coal/char to produce $\mathrm{CH}_{4}$ because of the low temperatures involved (Gregg and Edgar 1978; Kreinin and Shifrin 1993). The gasification time of UCG was extended by more than $30 \%$ using the RCG approach and the gasification rate of coal seams can be improved.

At the end of phase II, the temperature of the strata roof is lower than $690^{\circ} \mathrm{C}$, but it rapidly increased in the reverse combustion technique to reach higher temperatures as depicted in Fig. 12. The highest temperature reached was $1,300{ }^{\circ} \mathrm{C}$. Then reverse combustion gasification takes 


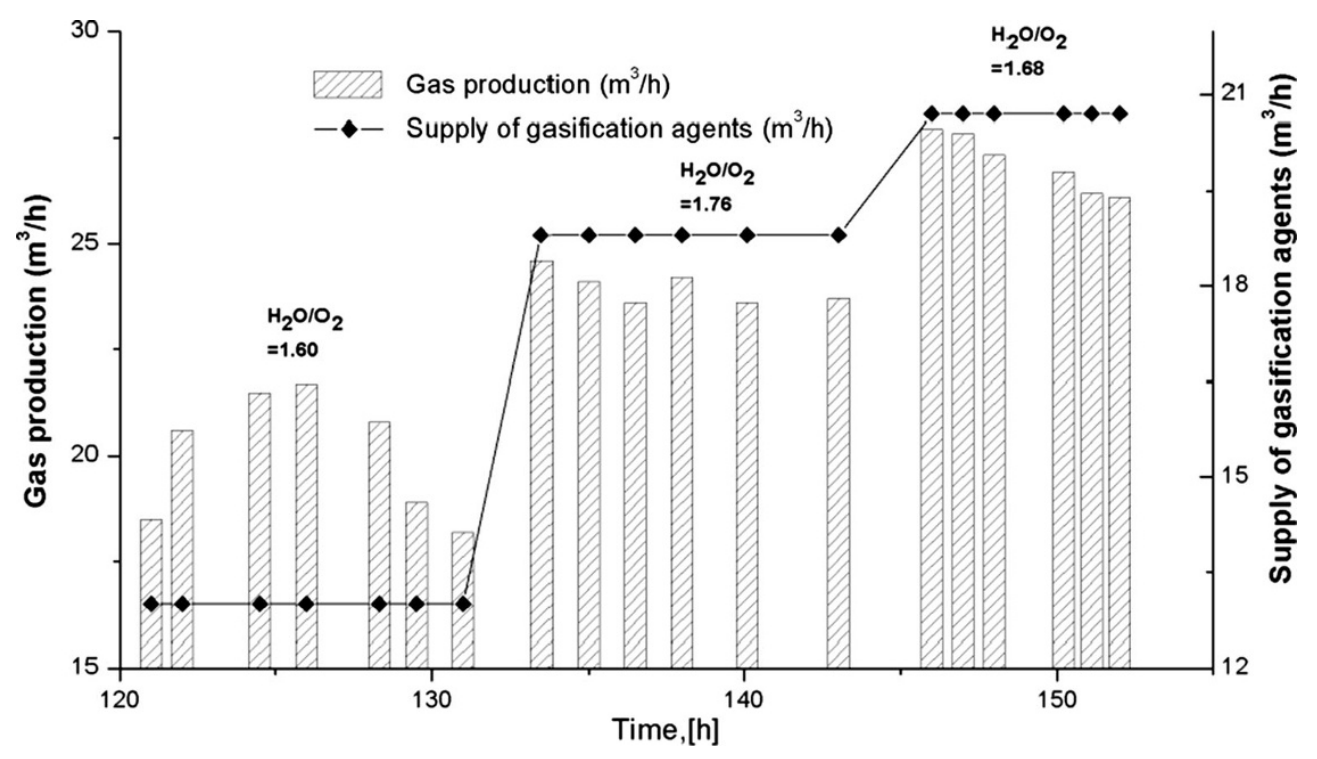

Fig. 11 Rates of gas production as a function of gasification agents rates and composition in the phase III

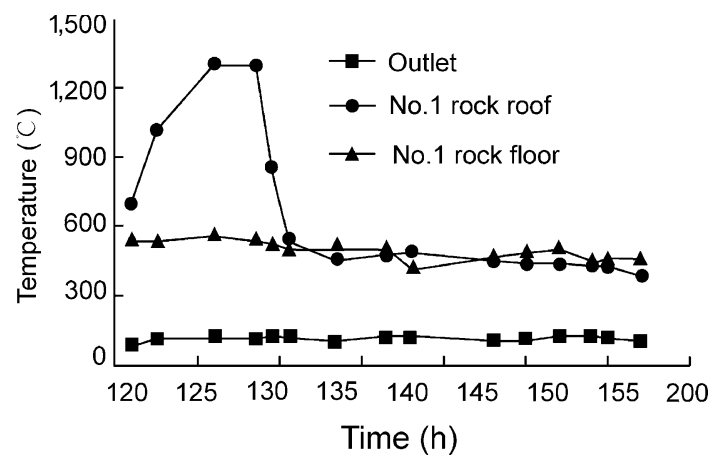

Fig. 12 Changes in temperatures of outlet syngas, strata floor and roof in phase III

place. After this state had been maintained for a few hours, the temperature in the strata roof and in the strata floor rapidly reduced. This phenomenon indicated that the reverse combustion flame rapidly moved from the gasifier center and proved that the reverse combustion rate is much higher than that of forward combustion (Blinderman et al. 2007). The temperature of outlet was stable at $100{ }^{\circ} \mathrm{C}$, which showed that the structure of the UCG gasifier could be maintained.

The oxygen and steam RCG process lasted for $33 \mathrm{~h}$, produced $770 \mathrm{~m}^{3}$ syngas, consumed an average of $0.319 \mathrm{~kg} / \mathrm{m}^{3}$ carbon and gasified $565 \mathrm{~kg}$ coal. The average gas production rate in this gasification period was $23.3 \mathrm{~m}^{3} / \mathrm{h}$.

\subsection{Nephograms of horizontal UCG temperature profiles}

The 2D nephogram of temperature profiles was used to investigate the temperature changes of the UCG process.
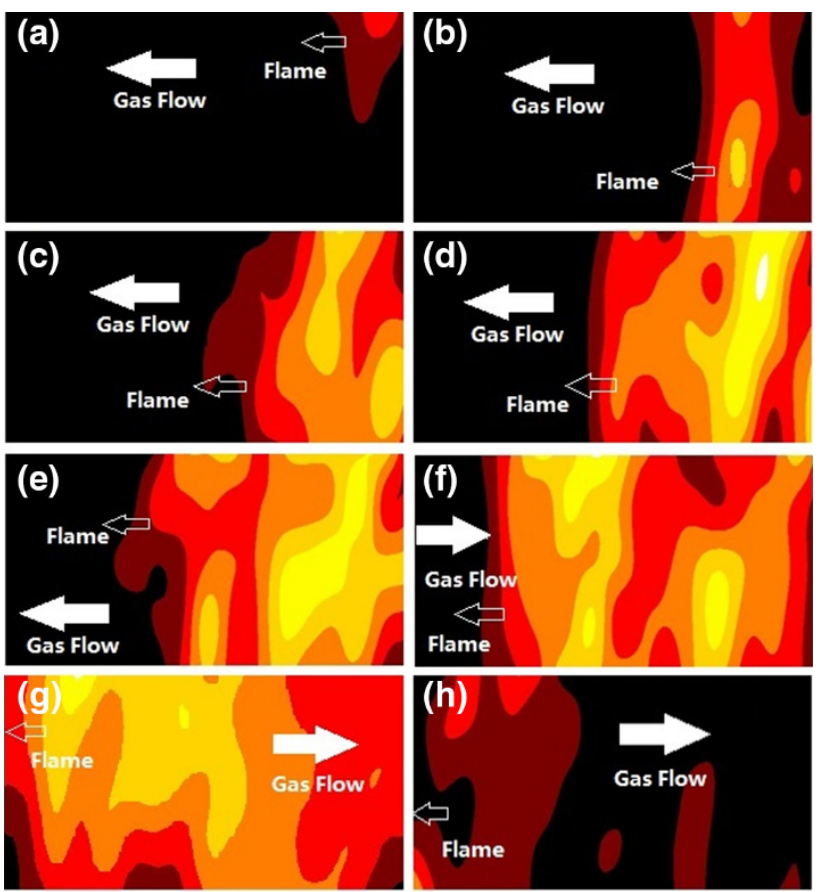

\begin{tabular}{l|l|l|l|l|l|l|l}
\hline $0-200$ & $200-400$ & $100-600$ & $600-800$ & $800-10001000-1200>1200$
\end{tabular}

Fig. 13 Nephogram of temperature profiles from the commencement of the process. a $5 \mathrm{~h} \mathrm{~b} 20 \mathrm{~h}$ c $40 \mathrm{~h}$ d $70 \mathrm{~h}$ e $90 \mathrm{~h} \mathrm{f} 120 \mathrm{~h} \mathrm{~g} 135 \mathrm{~h}$ h $140 \mathrm{~h}$

This method used Tecplot 360 CFD Visualization software to solve the conservation equations according to real temperature data from the 85 thermocouples in the coal seam, and horizontal temperature profile nephograms of the coal seam as a function of time are presented in Fig. 13. The computational domain on the level of the gasification 
channel was meshed using approximately 720 quadrilateral control volumes. Grid refinement studies showed that the solutions were grid independent (Perkins and Sahajwalla 2007).

The gasification flame propagated in the same direction during the whole experiments though the gasification gas agents flew in different orientation seen from Fig. 13. The results proved the experiment of RCG technology was successfully carried out. It was proved the feasibility of using RCG technique to gasify lignite with hydrogen-rich syngas whether FCG or RCG was applied to gasify lignite in UCG gasifier, the highest temperature was observed in those areas of the coal seam that were in close proximity to the oxidation/steam gasification center, i.e. at the flame head. The zone of oxidation/gasification reflected not only the gasification channel but also the level of the universal direction of coal seam due to the high permeability of lignite. Finally, the whole gasification flame surface gradually proceeded along the gasification channel and moved the product borehole. Since there was a $17^{\circ}$ inclination in the coal seam of the experimental system, the mass and heat should mainly transfer to the top left corner of inclination. Thus, the coal in this zone was essentially gasified.

\section{Conclusions}

(1) The model experiments proved the feasibility of producing hydrogen-rich and heating value syngas by applying the FCG and RCG techniques in underground coal gasification. In particular, the reverse combustion approach was used to successfully gasify lignite. The gasification time of UCG was extended by more than $30 \%$ using the RCG approach and the gasification rate of coal seams can be improved.

(2) An oxygen and steam continuous gasification approach, in which the oxygen and steam are fed simultaneously, can steadily maintain the composition of the syngas produced during the complete UCG process. The average hydrogen concentration was $39.6 \%$ with a maximum of $47.4 \%$, and the average $\mathrm{CO}$ concentration was $22.8 \%$ with a maximum of $27.4 \%$ during the FCG phase. The average hydrogen concentration was $39.7 \%$ with a maximum of $46.4 \%$, and the average $\mathrm{CO}$ concentration was $21.7 \%$ with a maximum of $25.9 \%$ during the RCG phase. Though the main role of the oxygen was to heat the coal seam, the average $\mathrm{H}_{2}$ and $\mathrm{CO}$ concentrations became $35.5 \%$ and $22.5 \%$, respectively. The optimal steam: oxygen volume ratio was the critical parameter for maintaining the high temperature in the gasifier and preventing lignite ash melting. The optimal range was found to be $1.5: 1-2: 1$ by analysis of experimental data. The average ratio value of steam and oxygen in FCG was slightly higher than the required for RCG.

(3) The theory of reverse combustion was briefly introduced in this work. According to the calculation, the supply rate of enriched oxygen was ascertained at $5 \mathrm{~m}^{3} / \mathrm{h}$, which was in agreement with experimental observations.

(4) From the gas composition measurements and the strata temperature profiles, it was found that an appropriately stable operation of the gasifier was achieved after about $50 \mathrm{~h}$ from the start of the process. The abundant heat was largely accumulated in the gasifier. It led to a favorable composition of the syngas produced in the UCG process and resulted in a heating value of the gas of $9.20 \mathrm{MJ} / \mathrm{m}^{3}$.

(5) To maintain appropriate conditions for obtaining hydrogen-rich syngas, the temperatures of the strata need to be monitored continuously in the various gasification phases. Temperature changes in the strata floor and the roof reflect the operating status of a simulated UCG gasifier. The reaction zones of oxidation/gasification could be deduced by analysis of the strata temperature and especially that of the roof.

Acknowledgments The work has been supported by the National High Technology Research and Development Program 863 of China (2011AA050106) and the Fundamental Research Funds for the Central Universities (2012YH01).

Open Access This article is distributed under the terms of the Creative Commons Attribution License which permits any use, distribution, and reproduction in any medium, provided the original author(s) and the source are credited.

\section{References}

Alejandro M, Fanor M (1998) Reactivity of coal gasification with steam and $\mathrm{CO}_{2}$. Fuel 77(15):1831-1839

Blinderman M, Klimenko A (2007) Theory of reverse combustion linking. Combust Flame 150:232-245

Blinderman M, Saulov D, Klimenko A (2007) Forward and reverse combustion linking in underground coal gasification. Energy 33:446-454

Dmitry N, Ovid A, Klimenko A (2010) Flame propagation in a gasification channel. Energy 35:1264-1273

Evgeny S, Arvind V (2009) Underground coal gasification: a brief review of current status. Ind Eng Chem Res 48(17):7865-7875

Friedmann SJ, Ravi U, Fung-Ming K (2009) Prospects for underground coal gasification in carbon-constrained world. Energy Procedia 2(274): 4551-4557

Gort R, 1995. On the propagation of a reaction front in a packed bed. Ph.D. thesis, Twente University, Enschede, The Netherlands

Gregg DW, Edgar TF (1978) Underground coal gasification. AIChE J 24:753-781 
Hans V, Jeroen V, Rob B, Philip D (2008) Reverse combustion: kinetically controlled and mass transfer controlled conversion front structures. Combust Flame 153:417-433

Hossein N, Mohammad K, Zhangxin C, Jalal A (2010) Simulation study of underground coal gasification in Alberta reservoirs: geological Structure and process modeling. Energy Fuels 24:3540-3550

Hurloff G (1983) Underground coal gasification cavity growth model. J Energy 7:410-415

Khadse A, Qayyumi M, Mahajani S, Aghalayam P (2007) Underground coal gasification: a new clean coal utilization technique for India. Energy 32:2061-2071

Kreinin E, Shifrin E (1993) Mathematical model of coal combustion and gasification in a passage of an underground gas generator. Combust Explos Shock Waves 29:148-154

Krzysztof S, Krzysztof K, Marian W, Jerzy S, Adam S, Jan R, Andrzej K (2012) Experimental simulation of hard coal underground gasification for hydrogen production. Fuel 91(1):40-50

Liu HT, Chen F, Pan X, Yao K, Liu SQ (2011) Method of oxygenenriched two-stage underground coal gasification. Min Sci Techno (China) 21:191-196

Park K, Edgar T (1987) Modeling of early cavity growth for underground coal gasification. Ind Eng Chem Res 26:237-246

Perkins G, Sahajwalla V (2005) A mathematical model for the chemical reaction of a semi-infinite block of coal in underground coal gasification. Energy Fuels 19(4):1679-1692

Perkins G, Sahajwalla V (2007) Modelling of heat and mass transport phenomena and chemical reaction in underground coal gasification. Chem Eng Res Des 85:243-329

Prabu V, Jayanti S (2011) Simulation of cavity formation in underground coal gasification using bore hole combustion experiments. Energy 36:5854-5864
Sateesh D, Ramesh N, Sanjay M, Anuradda G (2010) Laboratory studies on combustion cavity growth in lignite coal blocks in the context of underground coal gasification. Energy 35:2374-2386

Shugin L, Yuanyuaon W, Ke Z, Ning Y (2009) Enhanced-hydrogen gas production through underground gasification of lignite. Min Sci Tech 19:384-394

Singh S, Weil S, Babu S (1980) Thermodynamic analysis of coal gasification processes. Energy 5:905-914

Skafa P (1960) Underground coal gasification. Gosgortechizdat, Moscow

Stanczyk K, Howaniec N, Smolinski A, Swiadrowski J, Kapusta K, Wiatowski M, Grabowski J, Rogut J (2011) Gasification of lignite and hard coal with air and oxygen enriched air in a pilot scale ex situ reactor for underground gasification. Fuel 90(12):1953-1962

Yang L (2004) Study on the model experiment and numerical simulation for underground coal gasification. Fuel 83:573-584

Yang L, Liu S (2003) Numerical simulation on heat and mass transfer in the process of underground coal gasification. Numer Heat Transf Part A 44:537-557

Yang L, Liang J, Yu L (2003) Clean coal technology-study on the pilot project experiment of underground coal gasification. Energy 28:1445-1460

Yang L, Liu S, Yu L, Liang J (2007) Experimental study of shaftless underground gasification in thin high angle coal seams. Energy Fuels 21:2390-2397

Yang L, Zhang X, Liu S, Yu L, Zhang W (2008) Field test of largescale hydrogen manufacturing from underground coal gasification (UCG). Int J Hydrog Energy 33:1275-1285 